\title{
La descolonización en tiempos del Pachakutik
}

\author{
Graciela Mazorco Irureta \\ Universidad Mayor de San Simón, Cochabamba, Bolivia. \\ Email: gramaz@faces.umss.edu.bo
}

\begin{abstract}
Resumen: Vivimos un espacio-tiempo transformacional: el Pachakutik de los andinos. Indígenas e intelectuales occidentales exigen un cambio paradigmático para hacer viable la sobrevivencia de la especie humana. La descolonización se presenta como un proceso de deconstrucción de la alienación y subordinación del ser humano, y de simultánea construcción de un individuo autónomo y activo para edificar "otro mundo posible”. Aquí analizamos el riesgo recolonizador inserto en las propias visiones descolonizadoras, pues reproducen las dicotomías etnocéntricas entre colonizador y colonizado, o entre indio y occidental, potenciando los códigos que nos recolonizan diariamente. Afirmamos que la descolonización debe sustentarse en un nuevo paradigma filosófico -cuyas bases proponemos en este documento-, que responda a una cosmovisión alternativa y provea un lenguaje nuevo, ya que cualquier pensamiento que se formule en los mismos códigos discursivos que colonizan diariamente a la humanidad, será funcional al modelo de ser humano y de vida que ha impuesto la misma colonización.

Palabras clave: postmodernidad, interculturalidad, colonialidad del poder, descolonización, subalternidad.
\end{abstract}

\section{Decolonization in Pachakutik times}

Abstract: We live at a time-space of transformation: the Pachakutik of the Andeans. Occidental intellectuals and indigenous peoples demand a paradigmatic change to grant viability to the survival of the human species. Decolonization presents itself as a process of deconstructing the alienation and subordination of the human being, while simultaneously constructing an autonomous and active individual to edify "a different possible world". Here we analyze the risk of recolonization inserted into the visions proper to decolonization, thus reproducing the ethnocentric dichotomies between colonizers and colonized, or between indigenous and occidental people, empowering the codes that recolonize us on a daily matter. We affirm that decolonization must be sustained in a new philosophical paradigm - whose basis we propose in this document-, that responds to an alternative Cosmo vision that provides a new language, because any thought formulated in the same discursive codes that colonize humanity daily, will be functional to the model of humanity and life that colonization has imposed.

Key words: post modernism, interculturalism, colonialism of power, decolonization, subalternity.

\section{Descolonização em tempos de Pachakutik}

Resumo: Vivemos em uma transformação do espaço-tempo: o Pachakutik dos Andes. Índia e intelectuais ocidentais exigem uma mudança de paradigma em 
matéria de sobrevivência viável a da espécie humana. Descolonização é apresentada como um processo de desconstrução da alienação e subordinação de seres humanos, ea construção simultânea de uma pessoa ativa e autônoma de construir "um outro mundo possível”. Analisamos o risco recolonizar próprias visões embutido na descolonização, movendo-etnocêntrico dicotomias entre colonizador e colonizado, ou entre a Índia eo Ocidente, promovendo a re-code colonizar-nos diariamente. Nós afirmamos que a descolonização deve ser baseada em um novo paradigma filosófico cujas bases propostas neste documento “, que responde a uma visão alternativa e oferecer uma nova linguagem, porque qualquer pensamento que é feita dentro dos mesmos códigos discursivos que colonizam humano diário será funcional para o modelo ser humano e da vida que impôs mesmo assentamento.

Palavras-chave: pós-modernismo, multiculturalismo, colonialidade do poder, descolonização, subordinação.

\section{Introducción}

La descolonización es un encargo que ha asumido recientemente el gobierno indígena de Bolivia. Es entendida como una transformación paradigmática capaz de contribuir a la deconstrucción de las condiciones ideológico-materiales que colonizaron y recolonizan permanentemente la vida en la Tierra (así como proyectan colonizar la Luna y Marte), a la vez que a la construcción de los nuevos escenarios que harán posible salvar al planeta y la humanidad, a partir del sentimiento ancestral de unidad hombre-naturaleza.

También la descolonización forma parte del discurso postmoderno que, irradiado desde los centros europeos y norteamericanos de poder intelectual, embebe los debates que afronta el pensamiento postcolonial y postoccidental latinoamericano en su búsqueda de nuevos paradigmas que sirvan para revertir la subalternización del tercer mundo.

No es de extrañar, entonces, que la descolonización tenga significados tan variados como imprecisos, que la vuelven apta para todo y para nada, lo cual, contradictoria pero no azarosamente, hace a la descolonización muy útil a los propósitos de recolonización, como reflexionaremos en este documento.

En el plano ideológico-filosófico ${ }^{1}$, entendemos la descolonización como el proceso que permite al hombre erigirse en sujeto activo del cambio individual y social, para cuyo propósito debe liberarse de las estructuras inconscientes que condicionan su pensamiento y su lenguaje. Para ello es importante develar el poder oculto en los discursos y su efecto regulador o normalizador de comportamientos. Así, es posible luchar contra la dominación que opera en el ámbito de las representaciones simbólicas y se expresa en nuestras actitudes, emociones y conductas.

$\mathrm{Al}$ ser la filosofía una concepción general de mundo, del ser huma- 
no y del conocimiento, define las nociones comunes, es decir, el marco o paradigma que se aplica a todos los campos de la vida, inspirando las teorías y modelos en todos los niveles: de la política, economía, ciencia, religión, moral, etc. Esta concepción de realidad se comunica a través del lenguaje, el cual, a su vez, describe esa realidad en forma afín a cómo es pensada. De la filosofía provienen los códigos con que pensamos y decimos la realidad; ergo, distintas visiones de mundo serán correspondientes con sus respectivos marcos filosóficos, cognitivos y lingüísticos. Desde ese punto de vista, nuestra hipótesis es que cualquier llamado a la descolonización debe sustentarse en un nuevo paradigma filosófico, que responda a una visión de mundo y de hombre alternativa y que provea un lenguaje nuevo, ya que cualquier pensamiento que se formule en los mismos códigos discursivos que colonizan diariamente a la humanidad, será funcional al modelo de ser humano y de vida que ha impuesto la misma colonización, siendo que ésta opera, no única, pero prioritariamente, con la ideología transportada por el discurso.

Se trata, entonces, y esa es la intención que guía este documento, de desocultar lo oculto en el lenguaje con que se está formulado el problema de la descolonización, lo que éste esconde entre las palabras que dice, entendiendo que aquello que el sujeto piensa, dice y hace está, según la expresión de Foucault, condicionado por la episteme (conocimiento) de un momento histórico y una cultura particulares, que establece lo que es verdadero y lo que no, lo que está permitido y lo que no, constituyendo un real poder (el poder del conocimiento) que se usa para regular conductas, en tanto la sociedad acepta los discursos como verdaderos.

Es por ello que en este discurrir reflexivo queremos señalar que el tipo de energía que los discursos descolonizadores acarrean con la intención de aportar a la transformación paradigmática, desde uno y otro lado, corre el riesgo de desviarse en el sentido contrario, para reciclar la misma energía del sistema que se quiere transformar. Esto es así porque, tal como haremos evidente, se siguen reproduciendo las dicotomías etnocéntricas entre colonizador y colonizado, o entre indio y occidental, siendo que de esa manera se potencian los códigos que colonizaron y recolonizan diariamente a la humanidad, tanto en el norte como en el sur del planeta.

Dado que es nuestra intención potenciar la propuesta de cambio del modo de vida que impuso la civilización occidental, realizamos los aportes conceptuales en términos que provean de nuevas categorías filosóficas que hagan posible sustentar el cambio existencial de la especie humana, para hacer viable su sobrevivencia y pleno desenvolvimiento en el espacio-tiempo del Pachakutik.

\section{Posmodernidad y descolonización}

Desde las dos últimas décadas del siglo XX, la crisis de la modernidad ha generado como respuesta una serie de proyectos que pretenden tras- 
cenderla. Todos la presentan como una crisis esencialmente epistémica. Uno de ellos, el proyecto posmodernista, cuestiona, desde la misma Europa y Estados Unidos, la insuficiencia del conocimiento y la racionalidad moderna para dar cuenta de las transformaciones que se están dando en un mundo globalizado y diverso. Los otros proyectos, como los estudios subalternos, los postcoloniales y los postoccidentales, se formulan desde la subalternidad del tercer mundo y cuestionan al paradigma de la modernidad, entendido como el proyecto de occidentalización del planeta; pretenden instaurar un quiebre epistemológico que de lugar a todos los conocimientos que fueron subalternizados por la colonialidad del poder y del saber.

Mientras que la posmodernidad demanda un nuevo paradigma centrado en una nueva subjetividad para un mundo posmoderno construido y liderizado desde los centros de poder, a través del proceso de globalización, el pensamiento crítico latinoamericano denuncia que, siendo la colonialidad la otra cara de la modernidad, lo que cabe es hacer un llamado a la descolonización $^{2}$, lo cual implica no situar la mirada solamente en las transformaciones que se han venido dando en los últimos años (la globalización económica y cultural), sino ir mucho más atrás, hacia los procesos por los cuales se impuso y universalizó lo occidental ${ }^{3}$.

El nuevo humanismo posmoderno apela al desmantelamiento de la razón instrumental encarnada en el sujeto moderno cartesiano que nos legó la Ilustración, para abrir espacios subjetivos y epistemológicos plurales, claro que sin poner en tela de juicio el esquema civilizacional eurocentrista ${ }^{4}$.

Al trasladar el eje desde la economía hacia la cultura, el discurso de la posmodernidad es la sociedad multicultural y el reconocimiento de que otras culturas tienen sus propios modos de conocimiento válidos en sí mismos, aunque en los hechos no les reconoce un estatus epistémico ni ontológico alternativo al occidental. Es por eso que el discurso de respeto a la diferencia, tolerancia y diálogo en el conflicto no deja de ser un entramado simbólico creador de nuevos sentidos y significaciones funcionales a los requerimientos del sistema-mundo capitalista de la era global.

Como bien expresa Santiago Castro-Gómez ${ }^{5}$ : "La «globalización» es un fenómeno sui generis, pues conlleva un cambio cualitativo de los dispositivos mundiales de poder. La sujeción al sistema-mundo ya no se asegura mediante el control sobre el tiempo y sobre el cuerpo ejercido por instituciones como la fábrica o el colegio, sino por la producción de bienes simbólicos y por la seducción irresistible que estos ejercen sobre el imaginario del consumidor.” 6

Una vez que, con el fin de la guerra fría, renace el problema de la etnicidad, el objetivo de dominación planetaria requiere que los resistencias culturales contra el sistema, que ponen en peligro la estabilidad social del modelo de acumulación de capital y dificultan las operaciones de las multinacionales a lo largo y ancho del mundo, sean licuadas mediante la 
integración de las identidades conflictivas (aquellas cuya diferencia fue reprimida por la modernidad), al mundo globalizado. En otros casos, las diferencias son exacerbadas mediante estrategias ideológico-político-militares gestadas desde los centros de poder para "kosovisar" países, esto es: pedacearlos para neutralizar poderes antisistémicos emergentes, mediante la manipulación de enfrentamientos étnicos.

“Antes que reprimir las diferencias, como hacía el poder disciplinar de la modernidad, el poder libidinal de la posmodernidad las estimula y las produce”, con el objetivo de "modelar la totalidad de la psicología de los individuos, de tal manera que cada cual pueda construir reflexivamente su propia subjetividad sin necesidad de oponerse al sistema” (Castro-Gómez $\mathrm{s} / \mathrm{f})^{7}$. Recurriendo al lenguaje foucaultiano, se puede decir que la "racionalidad política"8 neoliberal especificó su propia forma de administrar el comportamiento y las emociones de la gente, definiendo el tipo de individuo funcional a la nueva variante de la economía del poder; éste es el "individuo autoprudencial”, aquel que se maneja racionalmente, cuyo destino depende de sí mismo y ya no necesita de un dispositivo mayor, como el Estado, para disciplinar su psiquis y su comportamiento. De esta manera, el individuo puede ser controlado de una forma más económica por el sistema, porque él mismo se autocontrola. Como el objetivo neoliberal fue achicar el Estado, el discurso enfatizó -y en esto contribuyó la aparición de un enorme caudal de literatura de autoayuda para superar dificultades, pensar positivamente y aprender a ser asertivos- la necesidad de que sean los propios individuos quienes asuman la responsabilidad por la gestión del propio yo, de su bienestar físico y psíquico. Arguyendo que el Estado de bienestar coartaba la iniciativa individual, fomentaba el asistencialismo y una cultura de la dependencia, el discurso neoliberal promovió que los individuos adquieran mayor autonomía y autogobierno, asegurando para sí la provisión de determinados bienes y servicios, como educación, salud, seguridad, pensiones, seguros, etc., y reduciendo con ello el gasto social del Estado en forma sustantiva.

Mientras tanto, en América Latina los intereses imperialistas se ven obstaculizados por la profundización de la contradicción entre naciones originarias y el modelo re-colonizador neo-neoliberal, creando el peligro de la acumulación de fuerzas de las bases populares y originarias. En ese marco, el nuevo léxico de la otredad _ el "reconocimiento del otro"_ no es más que una táctica conciliatoria que oculta la colonialidad del podē bajo el disfraz de la tolerancia y el pluralismo: categorías eurocéntricas propias del constructo teórico imperial, cuyo poder discursivo estructura actitudes que alientan la incorporación de los marginales (que amenazan con hacer caer el sistema) al proyecto renovado de re-colonización en el capitalismo transnacional tardío, lo cual conlleva completar el etnocidio de las sociedades indígenas que obstaculizan los planes de dominio territorial de las transnacionales.

La función del multiculturalismo posmoderno, dice la socióloga boliviana Silvia Rivera (2006:7), “es la de suplantar a las poblaciones indí- 
genas como sujetos de la historia, convertir sus luchas y demandas en ingredientes de una reingeniería cultural y estatal capaz de someterlas a su voluntad neutralizadora. Un «cambiar para que nada cambie», que otorgue reconocimientos retóricos y subordine clientelarmente a los indios en funciones puramente emblemáticas y simbólicas, una suerte de «pongueaje cultural» al servicio del espectáculo multicultural del estado y de los medios de comunicación masiva”.

Al mismo tiempo, ante el temor de que el factor étnico se constituya en el nuevo motor que aglutine a los movimientos sociales e indígenas en una categoría homogénea que impulse una propuesta civilizatoria alternativa, el tan mentado derecho a la diferencia no hace más que profundizar las contradicciones que dicotomizan unos de otros, fragmentándolos y enfrentándolos, para diluir su potencialidad antisistémica.

Entre la intelectualidad latinoamericana ligada a los proyectos postcoloniales y postaccidentales, se ha estructurado el grupo denominado “modernidad/colonialidad” (Castro-Gómez 2006), conformado por una serie de investigadores críticos ${ }^{9}$, muchos de ellos ligados a universidades estadounidenses (aspecto que no deja de ser tomado con serias reservas por parte de otros intelectuales latinoamericanos), y algunos relacionados con los movimientos indígenas (en Bolivia y Ecuador) o al Foro Social Mundial. Desde fines del siglo XX, este grupo ha contribuido a la crítica al eurocentrismo con una serie de categorías teóricas como: colonialidad del poder, diferencia colonial, descolonización, decolonialidad, por medio de las cuales la lectura crítica de la modernidad pone en evidencia las relaciones de dominación norte/sur que subalternizan al tercer mundo, constituyendo una perspectiva muy diferente a la que tiene la teoría crítica formulada por europeos y norteamericanos desde los centros del poder global.

La relación modernidad/colonialidad señala que la colonialidad es la otra cara de la modernidad. El filósofo argentino Enrique Dussel ha desmentido el mito de que la modernidad tiene origen intra-europeo, como un proceso madurativo que resulta de la sublimación de la razón, ya sea en su forma subjetiva (el idealismo subjetivo de Descartes) u objetiva (el idealismo objetivo de Hegel y el positivismo), generando la emancipación del sujeto, como yo-pensante, consciente de sí mismo y libre. Por el contrario, la modernidad no pudo existir sin la colonialidad: sin la conquista de América, el genocidio, el etnocidio y la exacción y explotación de sus riquezas. Por tanto, la modernidad se inicia con América, dando lugar a la configuración de un nuevo patrón de poder global: el sistema-mundo de Wallerstein (Lander 2001).

La categoría de colonialidad del poder es introducida por Quijano para describir la forma (colonial) que, a partir de la expansión colonial de Europa, asume el poder capitalista, al haber clasificado racialmente a la población del mundo, ubicando a unos grupos en el rango de subordinados, y a otros, en el de dominantes. A partir de esa primera discriminación racial, se fundan las "nuevas identidades societales de la colonialidad" (blan- 
cos, negros, amarillos, indios y mestizos), al igual que las geoculturales (Occidente o Europa, América, África, Oriente) y se impone una relación asimétrica de poder/subordinación en todos los ámbitos y dimensiones: materiales, subjetivas, individuales y sociales, bajo la hegemonía blanca y eurocéntrica de occidente (Quijano 2000).

Se pone así en evidencia cómo la colonialidad del poder creó la colonialidad del saber, esto es, la construcción del conocimiento ligada a la estructura de poder colonial, con el fin de legitimarla. De ese modo, el proceso colonizador subordinó el conocimiento producido fuera del primer mundo, calificándolo como saber local y subvalorizándolo como posibilidad de conocimiento frente a las teorías producidas en (y exportadas desde) Europa y Estados Unidos, las únicas que se atribuyen universalidad. En consecuencia, la categoría de descolonización que reivindica el pensamiento postcolonial y postoccidental que estamos analizando reclama el derecho a producir conocimiento legítimo desde América Latina.

\section{Descolonizando el saber}

La descolonización que demandan los estudios postoccidentales ${ }^{10}$ latinoamericanos exige el cambio epistemológico; esto es: descolonizar el saber para hacer posible que los subalternos puedan contar su propia historia y asumir su propia identidad, sin supeditación a los códigos eurocéntricos del saber y sin tener que verse como el reflejo imperfecto del primer mundo, siempre frustrados en una carrera por alcanzar la modernización (u occidentalización) en la que, desde el inicio, le estaba vedaba la posibilidad de ser como su modelo europeo, primero, y norteamericano, después.

La propuesta latinoamericana es: la "liberación epistemológica" que ponga a otras epistemologías (las locales) a dialogar con la occidental, construyendo una "epistemología fronteriza" como un conocimiento local crítico que se configura "en el punto de intersección entre historias locales y diseños globales”, que des-hegemonice la epistemología eurocéntrica y permita el diálogo de saberes (Mignolo s/ $\mathrm{f}^{11}$ ), o la construcción de una “epistemología del sur” (Boaventura de Sousa Santos, en Walsh, 2007) que otorgue legitimidad a los conocimientos alternativos.

La pregunta que está en el tapete es: ¿cómo es posible hacer todo eso sin subordinación al pensamiento dominante? ¿Cómo crear un conocimiento local que no esté contaminado por la visión de mundo eurocéntrica que ha colonizado nuestro ser y nuestro saber? ¿Cómo interpretar nuestra realidad con los anteojos conceptuales que nos colocó el colonizador, es decir, con los mismos códigos provenientes del saber hegemónico?

El problema que se perfila en torno a esta cruzada es que la misma colonialidad del poder que dividió racialmente al mundo entre civilización y barbarie, y estableció la dicotomía entre episteme (ciencia occidental) y doxa (ciencias otras), colonizó las mentes de los subalternos, modelándo- 
las para que no puedan pensar si no es bajo las categorías dominantes que impuso la visión racionalista de mundo consagrada por la filosofía occidental. Este conflicto está muy presente entre los intelectuales latinoamericanos que, preocupados por definir la identidad latinoamericana en tiempos de la globalización, se encuentran confrontados en dos grupos. Por un lado, los postoccidentalistas que trabajan en las universidades norteamericanas de élite y hablan de América Latina con un discurso que responde a los cánones académico-políticos de los centros de poder del primer mundo, enmarcado en la epistemología occidental, que es, justamente, lo que este grupo pretende trascender con la descolonización. Por otra parte, el pensamiento generado en América Latina, por sus propios intelectuales, reclama el derecho a hablar desde Latinoamérica, a partir de "sus propias categorías autorreflexivas y no desde categorizaciones extranjeras” (Achúgar ${ }^{12}$ s/f, cit. por González Castro), lo cual no deja de ser denunciado como un cierto "fundamentalismo latinoamericanista" (Mignolo 1998).

La propuesta descolonizadora del conocimiento pasa, al decir de Mignolo, porque los países del sur puedan tener una producción intelectual al mismo nivel que los del norte, no sólo para el tercer mundo, sino para el planeta entero, generando su propia elaboración teórica sin estar obligados a seguir los dictámenes epistemológicos y metodológicos que emanan del centro de poder científico instalado en USA y Europa.

¿Cuál será, entonces, el pensamiento local incontaminado que puede erigirse indómito frente al universalismo científico y proponer otra manera de concebir y construir conocimiento, que, a la vez, tenga legitimidad y poder para establecer un diálogo simétrico entre saberes? Esto es: ¿cómo generar un relacionamiento epistémico que no reproduzca la subalternización de sujetos y de saberes, sin sucumbir al eurocentrismo, al colonialismo y al racismo que impregnan las ciencias hegemónicas, y que, más bien, contribuya a la decolonización del conocimiento? (Walsh 2007).

Al hablar de pensamiento local tenemos que referirnos, por un lado, al pensamiento mestizo, aquel que proviene de su intelectualidad criolla (la clase letrada de América Latina), que asumió históricamente su subordinación ideológica y, aún en contra de sus intenciones independentistas, contribuyó a difundir y reproducir un saber colonizado y colonizante, destinado a reforzar la hegemonía teórica, política y económica del primer mundo. Son pocas, en consecuencia, las expectativas descolonizadoras que genera esta alternativa epistemológica.

Las reflexiones de Mignolo, Walsh y Castro-Gómez, aunque no en exclusiva, señalan al conocimiento ligado a tradiciones ancestrales como el más indicado para generar el descentramiento epistemológico que contribuya a la descolonización del saber en el tercer mundo, pues halla "sus bases en filosofías, cosmovisiones y racionalidades distintas” (Walsh 2007) "que ven el mundo como una totalidad en la que todo está relacionado con todo” (Castro-Gómez 2006:17). 
Esta es la perspectiva de interculturalidad formulada desde los movimientos indígenas, donde pensadores que nunca han pertenecido a los espacios académicos latinoamericanos hablan desde el "otro lado de la diferencia colonial”: desde su propia realidad indígena o afrolatinoamericana, y están haciendo una importante contribución al pensamiento a partir de categorías no-occidentales (Mignolo 2003).

La interculturalidad concebida desde los movimientos indígenas del Ecuador, analiza Catherine Walsh ${ }^{13}$, carece del sesgo colonialista con que la posmodernidad la considera como un problema del otro, es decir, como un problema étnico: del negro, del indio, aún del mestizo, pero no del occidental. Por el contrario ellos poseen una visión no etnocéntrica que les hace concebir la interculturalidad como mucho más que una lucha étnica, ya que, más allá de conseguir la inclusión de los grupos marginados, lo que pretenden es formular una respuesta civilizatoria alternativa que sirva para toda la humanidad (Walsh 2005). En la misma línea, el paradigma boliviano del Vivir Bien, estructurado recientemente desde la Cancillería de Bolivia, remite a la necesidad de un cambio en la modalidad de existencia, involucrando todos los planos de desenvolvimiento de lo humano.

Esta perspectiva tiene un alcance que supera enormemente la limitada consideración del problema colonial como esencialmente epistemológico (la colonialidad del saber), y nos lleva a reflexionarlo también y especialmente en el plano ontológico (como colonialidad del ser), que es lo que discutiremos a continuación.

\section{La descolonización del ser}

El tema de la descolonización debe constituirse en un espacio de reflexión que proponga nuevas formas de concebir no sólo la construcción de conocimientos, sino la propia condición del ser humano.

Mucho más allá del concepto de descolonización del saber, que ha sido formulado desde el pensamiento latinoamericano ligado a los centros académicos norteamericanos, y que pasa por poner en diálogo (probablemente de sordos) a los saberes subalternos con los dominantes, Catherine Walsh (2005: 23) propone la decolonialidad, en el sentido de: "[...] la reconstrucción radical de seres, del poder y del saber, es decir, la creación de condiciones radicalmente diferentes de existencia, conocimiento y del poder que podrían contribuir a la fabricación de sociedades distintas”. Este es un tema que ultrapasa lo meramente teórico: no se trata sólo de pensamiento crítico, sino también de praxis crítica: "construir alternativas a esta eurocentricidad" a través de "un proyecto de transformación social, política, epistémica y humana, [basado] en un imaginario o visión de un mundo de otro modo” (Walsh, 2005: 31). Así, mucho más que una modalidad de inserción o de resistencia de los movimientos indígenas, “[...] la interculturalidad construye un imaginario-otro de sociedad, permitiendo pensar y crear las condiciones para un poder social distinto, como también 
una condición social distinta tanto del conocimiento como de existencia” (Walsh 2005: 25).

Claro que el otro mundo que ellos conciben y proponen no constituye, en absoluto, un colonialismo invertido. Los sabios originarios muestran un profundo respeto a la identidad del otro y demandan un sistema de vida que dé cobijo a las distintas modalidades de ser, sentir, pensar y hacer en un relacionamiento armónico, una alimentación mutua o un proceso de intercambio que permite apropiarse de lo ajeno para fortalecer lo propio y profundizar la identidad de cada uno. Consideran tener en su cultura elementos valiosos que permiten construir un mundo más equilibrado, y pueden ponerlos a consideración de occidente, sin pretensiones hegemónicas. Del mismo modo, rechazan cualquier imposición de la cultura occidental, aunque no se resisten a tomar de ella lo que les sirva para su propio proyecto de vida, dentro de un Estado pluricultural (Caudillo s/f, cit, por Mazorco 2007).

La interculturalidad que se demanda desde la sabiduría ancestral es un relacionamiento sin dicotomías ni subordinaciones, basado en la complementación, el equilibrio, el consenso y el respeto a la identidad del otro. Como dice Silvia Rivera Cusicanqui (2006:12), es deseable una sociedad en la que mestizos e indios puedan convivir en igualdad de condiciones, aprendiendo mutuamente, uno del otro, modalidades de convivencia legítimas que permitan "formas nuevas de comunidad e identidades mezcladas o chhixi, con las cuales dialogarían creativamente en un proceso de intercambio de saberes, de estéticas y de éticas”. La categoría chhixi, propuesta por Rivera, es un aporte que, desde la sabiduría originaria andina, pretende desarticular los conceptos de hibridación y fundamentalismo, ambas categorías eurocéntricas que "encubren y renuevan prácticas efectivas de colonización y subalternación”.

El sentido de chhixi no debe entenderse como el mestizaje o hibridación que manejan García Canclini y otros intelectuales relacionados con los estudios culturales latinoamericanos, en el sentido de la disolución de anteriores identidades para configurar una nueva. "La noción de chhixi [...] obedece a la idea aymara de que algo es y no es a la vez, es decir, a la lógica del tercero incluido [...] es blanco y no es blanco a la vez, es blanco y también es negro, [...] lo chhixi conjuga el mundo indio con su opuesto, sin mezclarse nunca con él” (Rivera Cusicanqui 2006: 11).

En ese entendido, la opción epistemológica que ofrece el "pensamiento fronterizo" propuesto por Mignolo resulta insuficiente, dice Walsh, porque es una mediación entre el conocimiento dominante y el subalterno, que no elimina la eurocentricidad ni las relaciones asimétricas. Aunque el pensamiento local busque, cuestionándolo, abrir grietas por donde infiltrarse en el pensamiento eurocéntrico, rara vez éste considera la posibilidad de abrirse a otras perspectivas de conocimiento, como, por ejemplo, las indígenas. Peor aún, señala Silvia Rivera (2006), la propuesta de Mignolo neutraliza las prácticas descolonizantes, porque puede tentar a los intelectuales indígenas a reproducir conceptualizaciones que los alejan de sus raíces. 
La re-estructuración epistemológica es insuficiente y será también funcional si es que no va ligada a la construcción de una nueva ontología que re-evolucione la condición humana hacia otra modalidad de existencia (Mazorco 2007). Efectivamente, el conocer no es sólo un problema epistemológico, sino también ontológico: conocer es también cuestión de ser. El conocimiento racionalista occidental deriva de la ontología que separa al ser humano de la realidad, razón por la cual su epistemología separa al sujeto del objeto, y no puede encontrar la manera de unirlos, porque desde su sentimiento de separatividad no puede captar que el sujeto contiene al objeto, la mente contiene al mundo y viceversa.

Nuestro pronóstico indica que mientras el ser humano no abandone su antropocentrismo y dé el giro ontológico que le permita eliminar la separatividad y la jerarquía, no podrá dar con el cambio epistemológico tan buscado por la postmodernidad. El cambio ontológico (la descolonización del ser) exige la reunificación del ser con la realidad; unir al hombre con la naturaleza significa renunciar al antropocentrismo y volver a sentirse unido a la totalidad de la realidad, sin privilegios, con la humildad de ser un elemento más de la naturaleza, el cosmos y la totalidad de la realidad. Ello requiere dejar de vernos sólo en nuestro diferencial de humanos y comenzar a sentir nuestra semejanza natural y cósmica con todos los demás seres, esto es, concebirnos como un ser humano integral.

\section{El giro civilizacional: la unidad}

Desde que la cultura occidental y cristiana se expandió por el mundo entero, imponiendo su modo de ser-sentir-saber-hacer, el europeo, como el modelo dominante, se estableció como válido un único fundamento filosófico, es decir, un única visión de mundo, de ser humano y de conocimiento, subsumiendo a otras filosofías en la categoría de no-filosofías y a otras modalidades de existencia en categorías como primitivismo, barbarie o nocivilizacionalidad.

Sabemos que la diversidad es el pilar de la vida en la Tierra; sin embargo, la civilización occidental ha recelado de lo diverso, es decir, de lo otro, lo no igual, lo desemejante, lo diferente, porque, por su sentimiento de estar separado de la naturaleza y el cosmos, siente que el otro es el noyo, es lo extraño, lo no conocido, lo no confiable, lo caótico, lo que es necesario dominar y controlar.

Esta visión de mundo y modalidad de existencia, a la que podemos denominar civilización de la no unidad, se hizo hegemónica y arrinconó, sin destruir, a otra civilización que, expandida por todo el planeta, incluía semejantes-diferentes grupos humanos, diferentes-semejantes culturas que compartían el sentimiento de unidad con la totalidad de la realidad, que se sentían seres humanos, naturales y cósmicos que vivían sin dicotomías pese a sus diferencias de forma, respetando a cada uno de los otros seres, sean humanos, naturales o cósmicos, con los que se complementaban, 
consensuaban y equilibraban en su cotidiano vivir. Desde ese sentimiento, el humano no está al centro; cada uno tiene su lugar, sin jerarquías, dentro de una totalidad energética, en la cual todo está unido, aunque nos parezca separado y autónomo.

Desde esta cosmovisión, cosmosentimiento y cosmovivencia, la realidad es una unidad estructural vibratoria de materia-energía, o de partícula-onda, de modo que cada uno-todo traspasa e intercambia energías-materias con los otros uno-todo diferentes-semejantes. De ahí que su epistemología, coherente con el sentimiento de unidad entre el ser y la naturaleza, expresa que el cosmocimiento y sabiduría son energía-materia. El cosmocer es un proceso de combinación e intracombinación de energíamateria; no es un proceso puramente mental, aunque lo mental es también energía-materia. De ese modo, "la realidad no sólo se aprehende: se ES. La realidad se produce, reproduce y recrea en lo humano, que se llena de la realidad” (Gonzáles e Illescas 2002).

A esta antigua civilización de unidad pertenecemos, por herencia genética, todos los seres humanos. En nuestros genes está guardada la memoria histórica de esa humanidad que vivió en unidad con la totalidad, es decir, como seres humanos integrales, que se sabían humanos, pero también naturales y cósmicos, sin antropocentrismo ni etnocentrismos. Es esa una condición ontológica del ser humano y del ser de la totalidad que ha perdido hegemonía, pero no ha desaparecido de las mentes y corazones de millones de individuos que ahora están en condiciones de revertir su alienación en autodeterminación. (Ibíd.).

La colonización resulta ser, en consecuencia, la pérdida de identidad de ese ser humano integral, el cual resultó alienado, es decir que perdió su condición natural y cósmica para devenir en la persona humana, antropocéntrica y dicotómica, producto final de todo un proceso de deshumanización que ha convertido al individuo en una mercancía, objeto o cosa manipulada y no autodeterminada, capaz de conducir a la humanidad al abismo de su propia subsistencia.

La persona humana está programada no sólo por la ideología, sino también por la alimentación. Occidente asegura el dominio ideológico a través del lenguaje, el cual, como energía-materia, interpenetra el pensamiento y el sentimiento, alienando al individuo, no sólo en las culturas no occidentales, sino en el propio corazón de los países centros del poder.

Por su parte, la alimentación está cada vez más diseñada, producida y distribuida por transnacionales que manejan los hilos de la marionetapersona humana, con el fin de desbiologizarla, al torcer los equilibrios metabólicos, y homogeneizarla bajo un modelo de individuo irreflexivo, sumiso y enfermo; al mismo tiempo, esa alimentación artificializada descosmologiza a lo humano, pues lo desincroniza de los períodos, ritmos, ciclos, frecuencias o constantes telúricas y cósmicas que rigen la crianza natural de alimentos, tanto como de la vida humana. El comportamiento, 
las emociones y la lucidez de una persona están afectadas por lo que come: somos lo que comemos. La homogeneización de la alimentación destruye identidades al unificarlas en función de un patrón global de ser humano necesario para la producción y reproducción del capital.

Grimaldo Rengifo (1999) dice que: "En los Andes la comida es vivenciada como una persona que cría a los humanos mientras también es criada por éstos [...] es madre vida y generadora de vida [...] Los alimentos pasan turnos para alimentar a los runas (humanos)”. Esto quiere decir que los alimentos vienen y se van siguiendo los ciclos telúricos y cósmicos, de modo que el humano tenga una alimentación variada y sincronizada con la naturaleza. Al fin y al cabo, "es sólo a partir de la biodiversidad de alimentos que los seres humanos pueden ser también diversos” (Arispe 2008).

"Entre comida y humanos la relación es una conversación en que se interpenetran sabores pero también modos de ser [...] los atributos de una determinada comida devienen en atributos del ser que la come”. En occidente, en cambio, la comida está reducida analíticamente a una serie de componentes (proteínas, hidratos de carbono, grasas y vitaminas), para cada uno de cuales se formulan indicadores universales y cuantitativos de consumo diario para asegurar el "mantenimiento del organismo máquina”, esto es: "estar físicamente sano y apto para el trabajo", a partir de llenar "un estómago universal o más bien global” (Rengifo 1999).

Esta universalidad ignora las identidades particulares de cada individuo que, en función de su diferencia-semejanza, se puede complementar equilibradamente con determinado tipo de alimentos, pero no con todos. Incluso, según la teoría de los grupos sanguíneos y la alimentación, formulada por Peter D’Adamo (1998) la dieta óptima para una grupo sanguíneo, resulta desequilibrante (enfermante) para otro, ya que cada alimento tiene sus lectinas (proteínas) específicas, las que resultan compatibles, por la semejanza celular, con un grupo, e incompatibles, por la diferencia, con otros. Entre los alimentos incompatibles con la mayoría de la población mundial, D’Adamo señala la leche y el trigo, los cuales son, contradictoria pero no casualmente, la base de la alimentación introducida por el colonizador y difundida hoy por las transnacionales (Nestlé, Kraft, General Foods, Arcor, Danone y otras, en el nivel de la producción, y Carrefour, Walmart, Sainsbury, Jumbo, Makro y otros, en la distribución) que siguen colonizando no sólo tierras, territorios y recursos naturales, sino también los estómagos de las personas.

La globalización de estos alimentos está sustituyendo cada vez más a los alimentos de las comunidades rurales, como la papa, maíz, frijoles, quínoa, amaranto, cañawa y otros, no sólo con "valores nutritivos" enormemente superiores a la leche y al trigo, sino complementarios con la identidad de sus criadores, pues constituyen su entorno natural, equilibrado con las condiciones de clima y de altura en la que viven. 
Esta es la lógica que domina la producción mundial de alimentos, la cual persigue la correlativa producción caricaturesca de un humano homogéneo y sin capacidad de autodeterminación. Esta forma de recolonización desorganiza identidades y programa autómatas mediante la desestructuración biológica del individuo, al constreñirlos a consumir alimentos incompatibles con la salud y con la lucidez mental de las personas. Al respecto, la teoría del estómago como un segundo cerebro ya ha precisado la forma en que lo que metemos en el vientre determina comportamientos y emociones, condicionando nuestra lucidez u opacidad mental. Esto es así, porque el denominado cerebro entérico tiene tantas células nerviosas como la médula espinal y produce tantos neurotransmisores como el cerebro. La conexión entre los dos cerebros es muy intensa, pero, afirma el profesor Michael D. Gershon, jefe del Departamento de Anatomía y Biología celular de la Universidad de Columbia, en Nueva York, se producen más comunicaciones (mensajes) desde el estómago al cerebro que a la inversa. Esto hace que: "Ningún pensamiento fluye con normalidad cuando la conciencia entérica está puesta en el retrete”, ironiza el profesor Gershon, quien también afirma que cuando Descartes dijo: "Pienso, luego existo", seguramente estaba con sus intestinos en un muy buen estado digestivo. (Arispe 2008).

Si bien el proceso de alienación del ser humano integral estuvo presente en los fenómenos de conquista del llamado tercer mundo, con el establecimiento de colonias dependientes del primer mundo, no ha operado exclusivamente por este medio; pensemos, por ejemplo, en cómo desde los griegos presocráticos (los filósofos de la naturaleza) se ha ido dando forma a una nueva forma de pensar y sentir que, terminando con el sentimiento de unidad que todavía se expresaba en la mitología griega, y aún entre los mismos filósofos griegos, configuró la racionalidad antropocéntrica que dominó poco a poco a la filosofía y a la ciencia occidental. Con esto queremos decir que el colonialismo, como internalización hegemónica de los códigos de la no-unidad, no nace en el momento de la expansión colonial de Europa, sino previamente, y ya en la misma Europa. Por tanto, el ser que hay que descolonizar no es sólo el ser que el sometimiento colonial subhumanizó e infra-dimensionó con respecto al modelo occidental de ser humano. La colonialidad del ser es un fenómeno que compromete tanto al colonizado como al colonizador.

El proyecto que sub-humaniza a los subalternos del poder colonial, al degradarlos por su condición de raza, género, sexualidad o religión, también degrada al hombre blanco, cristiano y europeo, involucionándolo, al igual que los otros, a la condición de "persona humana", no natural ni cósmica, soberbia y necia, ciega para ver que está destruyendo el seno materno que sustenta su condición de existencia en la Tierra.

Si bien la "colonialidad del poder”, como categoría crítica, denuncia y reclama por la otredad constituida en base a diferencias en las formas (el otro es el indio, el negro, el mestizo, la mujer, el homosexual, el minusválido, el no cristiano) resulta insuficiente para explicar la diferencia esencial: la diferencia ontológica entre los seres que se sienten unidos y los 
que se han separado de la totalidad. Esta transversaliza a todos los seres del planeta, ultrapasando la visión dicotómica que enfrenta a blancos, mestizos e indígenas, y al primer con el tercer mundo.

Negamos con ello las dicotomías "norte-sur” o "primer mundo-tercer mundo" que están presentes en el concepto de descolonización que emana de las categorías conceptuales postoccidentales. Tampoco estamos de acuerdo con la contradicción "indio-occidental" que maneja en su discurso descolonizador el Estado boliviano, porque ella reproduce la dicotomía racista colonial, sin apelación alguna a la diferencia ontológica que estamos considerando. Tales oposiciones suponen que la descolonización atañe sólo a uno de los extremos de la díada, dejando al otro afuera; ello trasluce el enfrentamiento entre lo correcto y lo incorrecto, lo bueno y lo malo, cada uno habitando geografías específicas, lo cual nos lleva, sin dudas, a un recalentamiento de los racismos que constituyen la diferencia colonial a que alude Mignolo.

Lo que estamos esbozando es un conflicto inter-civilizacional entre la civilización de la no unidad (extendida por todo el planeta y encarnada en las mentes y corazones de cada uno de los individuos de este mundo) y la civilización de la unidad, que duerme, en letargo en algunos, más activa en otros, también en todos los seres humanos de la Tierra, independientemente de la circunscripciones geopolíticas o culturales a las que pudiéramos referirlos. Ergo, hablar de dos mundos o dos civilizaciones no significa que estemos planteando una dicotomía étnica ni un choque de civilizaciones entre occidente y el resto del mundo. Cuando concebimos la colonización en el sentido de la alienación o pérdida de identidad ancestral (la del ser humano integral), la descolonización nos atañe a todos y no nos enfrenta a nadie, salvo con nosotros mismos, pues se trata de un proceso de desalienación que debe darse al interior de cada uno para despertar el ser humano integral que duerme en la memoria histórica contenida en nuestros genes.

No se trata, entonces, de enfrentamientos armados para destruir al otro, al colonizador, pues él mismo está en nosotros, al haber internalizado sus códigos. No se trata tampoco de nuevos adoctrinamientos formulados desde quien está ahora en posesión de la "nueva verdad", para adoctrinar al otro, el que queda del otro lado de la diferencia colonial, ahora invertida. No se trata de indianizar al país o al mundo ni de levantar al sur contra el norte (sendos nuevos etnocentrismos), sino de despertar las visiones ancestrales que nos pertenecen a todos, y ponerlas a conversar entre ellas, para consensuar, pese a las diferencias de forma, la semejanza esencial ontológica.

Por lo tanto, el nuevo/viejo paradigma de la unidad no tiene ningún contenido etnocentrista y es extensible a todo ser humano, de cualquier clase social, nacionalidad, etnia o cultura que siente y piensa la necesidad de otra opción de vida. Eso le da un carácter tan universal como el del paradigma eurocéntrico, y nos permite romper con el sub-calificativo de 
“local” con que se desacredita y folcloriza el pensamiento no-occidental.

Por otro lado, las culturas hoy llamadas originarias han perdido, en mayor o menor medida, su vivencia y pensamiento de unidad como efecto de las sucesivas oleadas colonizadoras: la cristianización, la misión civilizadora, el desarrollo y la modernización, y últimamente, la posmodernización. Por la colonialidad del poder, el conocimiento ancestral no sólo fue subalternizado y destruido, sino también torcido, o sea penetrado por códigos occidentales, como caballo de Troya, con fines estratégicos de alienación. Por ejemplo, la propuesta de la interculturalidad que manejan los pueblos indígenas incorpora el lema de "unidad en la diversidad" ${ }^{14}$, sin reflexionar que el mismo ha sido promocionado, no casualmente, por el pensamiento complejo. Es Edgar Morin, el teórico de la complejidad, quien ha postulado la idea de la diversidad (la diferencia) como esencia de la unidad, en forma coherente con el paradigma occidental, para el cual es la escisión, y no la unidad, la esencia de la realidad.

Resulta, entonces, que la "unidad/diversidad", como vacuna eurocéntrica contra el virus de la unidad -que resulta disfuncional al sistema- ha logrado su objetivo estratégico de “dividir para reinar”, pues se han profundizado los etnocentrismos, generando mayores separaciones y reproduciendo subordinaciones coloniales, no sólo entre indios y blancos, sino, además, entre diferentes grupos étnicos; por ejemplo, entre andinos y amazónicos o entre indígenas y afrodescendientes.

Otro caballo de Troya posmoderno es "la complementariedad de opuestos" que, traída por el pensamiento complejo, ha sido asumida como un código originario por algunos intelectuales indígenas. La dialógica de la complementación de opuestos pretende superar a la dialéctica de la contradicción, cuando, en su esencia, la está manteniendo, ya que el opuesto es la expresión de la contradicción: es el otro, el no-yo, el diferente. Y la contradicción es la esencia de la ontología y la epistemología de occidente, que estructura la identidad, el imaginario y el hacer de los individuos en torno a la identificación de su diferencia con los otros seres, potenciando actitudes jerarquizadoras y subordinadoras que intensifican las divisiones entre los seres humanos, y entre éstos y la naturaleza. Por ello, la diferencia es la herramienta ideológica que le sirve al sistema para perseverar en la colonialidad de poder. He ahí que al hablar de la complementación de opuestos, como un supuesto principio de la sabiduría originaria, se está, de entrada, torciendo el mismo fundamento de unidad que expresa este pensamiento en su configuración ancestral, desde el cual no existe en la realidad lo opuesto, sino lo diferente-semejante.

No sólo desde las culturas originarias, sino también desde la física cuántica, la microbiología y la genética se gesta una nueva propuesta ontológica y epistemológica. Hay que recuperar el saber de los indígenas: quechuas, aymaras, amazónicos, ecuatorianos, mayas, dakotas, africanos, australianos, chinos, tibetanos, etc., etc., pero también el de los que podría- 
mos denominar "indígenas europeos”, es decir, de aquellos que, proviniendo de grupos no identificables con lo racial y culturalmente considerado como "indígena” (al fin este es un término eurocéntrico que debemos deconstruir para descolonizar), no dejan de poseer la información del saber ancestral originario. El saber, por su característica material-energética, se concentra-desconcentra en los genes y se transmite de generación en generación por la carga herencial-material. Pese a que el saber ancestral ha sido y continúa hoy siendo deformado a través de las crónicas de los colonizadores y actualmente por la antropología, arqueología, etnología, lingüística, historia, sociología, educación, psicología, geología y otras ciencias orientadas al etnocidio, se tiene en los genes la información de todo lo vivido en lo inmediato y mediato, así como en la regresividad histórica más remota (Gonzáles e Illescas 2002).

Pero también, y teniendo en cuenta que la ciencia es una parte de todo el saber, debemos nutrirnos de los aportes de la ciencia occidental a la construcción de categorías que apuntan a la reconstrucción de los espacios vitales y expresan cada vez más coincidencias con la visión ancestral de la realidad como un tejido de vida. Sin embargo, en ambos casos hay que estar atentos a no sucumbir ante los códigos occidentales que colonizan nuestro pensamiento y nuestro lenguaje.

\section{El nuevo lenguaje de la unidad}

La descolonización del ser, combinada con la construcción del ser humano integral, exige que se abran espacios en los que sea posible no sólo otra forma de ser-saber (ambos son una unidad, ya que se corresponden como dos caras de una moneda), sino también otra forma de hablar, de alimentarse, de relacionarse con el otro, de hacer economía, juricidad ${ }^{15}$, culturalidad, política, arte y vida cotidiana, que sean coherentes con la modalidad de existir y conocer expresiva del sentimiento de estar unido a la realidad.

Cuando decimos: otra forma de hablar nos referimos a la necesidad de recuperar las categorías conceptuales de una "filosofía”16 ancestral que, en los diferentes idiomas, exprese el pensamiento y sentimiento originario de unidad con la naturaleza. De lo contrario, todo intento de transformar el sistema de poder utilizando sus propios fundamentos filosófico-ideológicos transmuta en, o más bien lleva en sí mismo, una utopía.

Hay que tener en cuenta que no sólo los lenguajes occidentales están codificados para expresar el pensamiento y sentimiento eurocéntrico dominante, de modo que no se trata, como algunos indígenocentristas proponen, de aprender a hablar las lenguas indígenas. También los lenguajes originarios fueron desvirtuados y antropocentrizados por los extirpadores de lenguas e idolatrías, siendo desfigurados y/o eliminados todos los significados y símbolos expresivos del pensamiento-sentimiento de unidad ${ }^{17}$ para volverlos aptos a la evangelización colonizadora; ergo, ellos también me- 
recen una depuración lingüística ligada a la reconstrucción de sus propios códigos.

La propuesta teórica es el cambio del discurso, del marco teórico, conceptual y metodológico. El lenguaje de unidad no puede contener categorías, conceptos, juicios de la no unidad; tiene que ser un lenguaje diferente que denote y connote la unidad y sus realidades. En principio, debemos deconstruir la dicotomía entre occidente y no occidente. Todos somos occidentales y no occidentales a la vez, en tanto guardamos en cada una de nuestras células la información codificada de la unidad como de la no unidad, al mismo tiempo. Esto es: todos somos chhixi, occidentales y no occidentales, o indígenas y no indígenas, al mismo tiempo. Por la misma razón, debe deponerse la actitud occidentalista (eurocentrista) que asume lo indígena como una realidad separada y externa (es decir: opuesta), con la cual, a lo más, hay que ponerse a dialogar para complementar saberes. Pero también es dicotómica la posición inversa (indígenocentrista) que pretende indianizar sociedades, porque en ella está implícito el reconocimiento de que el indio y el no-indio son dos realidades antagónicas e irreconciliables y de que ha llegado el tiempo de la negación del otro occidental.

Consecuentemente, no se trata de excluir al occidente de esta o de ninguna otra propuesta de cambio de vida, ni de negarle el potencial de contribuir a la construcción de otro mundo posible. Eso es exactamente lo que hizo occidente cuando impuso, sin consultar, su propuesta para "salvar” las almas primitivas de los bárbaros con el modelo civilizacional racionalista y evangelizante: se arrogó una verdad de la cual excluyó al otro, y se adjudicó la función salvacionista de una humanidad sub-humanizada que, según el dictamen eurocéntrico, vivía en la oscuridad de la ignorancia y no tenía ninguna posibilidad de ascender, por sí misma, al podio de las luces.

No se trata de alternar el ejercicio etnocéntrico y pensar que occidente no puede debatir y aportar a la construcción de una existencia humana en armonía con la madre naturaleza. Si se le proyecta esa incapacidad e ignorancia, se estará considerando que es occidente quien ahora debe ser salvado por el otro desenterrado, lo que no hace más que reproducir las mismas actitudes colonizadoras que guiaron el proyecto de la modernidad. Antes bien, es fundamental cerrar toda posibilidad de bipolaridad ideológica y abrirse a múltiples visiones de realidad, de ser humano y de conocimiento, incluida la indígena, pero no en exclusiva, porque eso trasluciría un nuevo etnocentrismo o una inversión del actual etno-eurocentrismo. Ergo, debemos borrar las dicotomías entre lo indígena y lo occidental, para dar lugar al equilibrio simétrico entre diferentes-semejantes, tal que unos puedan aprender de otros, y viceversa, para desenvolver plenamente el potencial de armonía entre hombre y naturaleza que duerme en todos, sin discriminación racial ni cultural alguna.

Sólo incluyendo a occidente será posible cancelar la sistemática recolonización a la que nos somete diariamente su modelo eurocéntrico, por- 
que si lo excluimos estaremos funcionalizándonos en su propio juego de dicotomía, negación, exclusión, marginación y subalternización del otro, y reproduciremos el paradigma civilizacional que pretendemos combatir.

Para deponer los etnocentrismos de uno y otro lado es necesario deconstruir el discurso de la diferencia, convertido en el eje central de multiculturalismo eurocéntrico, tanto como de posiciones indígenas que reivindican "la unidad en la diversidad". En su lugar, adoptar el código de la diferencia-semejanza, entendiendo y sintiendo que cada ser es diferente-semejante, al mismo tiempo, a todos los demás seres. De tal modo, en su semejanza, cada uno es el otro, a pesar de las diferencias. Por ejemplo, nuestros genes son $99 \%$ semejantes a los de un chimpancé y $70 \%$ a los de un ratón; con lo cual estamos marcando más semejanzas que diferencias, y podemos empezar a destituir el antropocentrismo, como categoría establecida a partir de la diferencia, para comprender cuánto contenemos, cada uno de nosotros, de los demás seres de la totalidad.

El código de la semejanza-diferencia nos lleva a deconstruir también el código occidental de la contradicción, como esencia de las transformaciones de la realidad. La contradicción se basa en la diferencia que antagoniza a dos opuestos (tesis-antitesis), los cuales luchan por superarse secuencialmente en un tercero (síntesis) que no es ninguno de los dos anteriores. La semejanza-diferencia no permite concebir opuestos, ni secuenciamientos lineales de tesis-antitesis-síntesis, y nos plantea, en cambio, la combinación e intracombinación de energías-materias que se interpenetran todo el tiempo, de modo que los semejantes-diferentes elementos se contienen mutuamente. En ese sentido, cada uno es sí mismo, y no lo es, pues, al mismo tiempo, es, sin ninguna contradicción, el otro. Los aparentemente opuestos son manifestaciones de la misma cosa, y no dos cosas separadas, ni reciben carga valorativa alguna, del tipo: bueno-malo o verdadero-falso. Este pensamiento era expresado por Heráclito, diciendo que no existe la separación de opuestos, pues forman un todo continuo donde ninguno acaba por imponerse y anular al otro, y entre ellos prima el equilibrio.

\section{Pachakutik y autopachakutik}

La negación de la contradicción nos lleva, en consecuencia, a pensar que la unidad y la no-unidad son ambas manifestaciones de la misma realidad, y no son contradictorias; por tanto, no podemos pensar que una es la correcta y otra la incorrecta. ¿Por qué, entonces, estamos reclamando el cambio civilizacional para toda la humanidad?

El maestro inka, José Illescas ${ }^{18}$, nos aclara que la unidad y la no unidad no son elementos separados, sino que conforman una unidad o un uno-todo; históricamente han coexistido y coexisten, interpenetrando una a la otra, en equilibrio simétrico, a veces, o con hegemonía de una sobre la otra, lo que no deja de expresar una modalidad semejante-diferente de equi- 
librio, que podríamos denominar asimétrico.

De acuerdo con Gonzáles e Illescas (2002), la no unidad de hoy se equilibra con un ciclo o frecuencia de la Pacha, así como la unidad ancestral se equilibraba con otra modalidad frecuencial de la realidad. Sin embargo, hoy la Pacha está en su Pachakutik que recambia a la no unidad, pues ha agotado su espacio-tiempo, por el nuevo orden de la unidad. Son las condiciones de la Pacha las que determinan su propio kutik, el que permeabiliza a todo lo existente, sin llegar a determinar (porque no hay determinismo de ninguna clase en la unidad) el cambio del ser humano. Todo individuo (sea o no originario de Abya-Yala), como cualquier otro ser de la realidad, son autodeterminados y pueden optar -o no- por autoprocesar su propio kutik, consensuadamente, en complementación y equilibrio con el cambio de la totalidad, desenrollando su identidad en unidad con la Pacha. Las condiciones de la Pacha, del cosmos, de la naturaleza, de la Tierra y de la humanidad están dadas.

Se trata de una coexistencia y superposición de energías constructivas y destructivas que hace posible la autodeterminación del individuo para re-evolucionarse hacia la condición de ser humano integral, así como el resurgir de las sociedades-culturas-civilizaciones milenarias de la unidad ancestral originaria, sin ningún etnocentrismo, racismo ni antropocentrismo. Por esa unidad de la construcción-destrucción, en este proceso viviremos combinadamente, en forma simultánea: la descomposición del capitalismo, su ideología y la pérdida de la hegemonía de occidente; la agudización de la lucha o guerra de clases y guerra de naciones; la profundización de los conflictos interimperialistas en lo económico, financiero, comercial, científico, tecnológico, social, político, jurídico, cultural, ideológico, militar, etc.; una mayor agresión a la naturaleza, a la Tierra y al cosmos y una acelerada deshumanización, desbiologización y desplanetalización de las grandes masas, que están siendo programadas y controladas por la alienación y enajenación que impulsa el sistema, en gran parte a través de la ofensiva de los medios de comunicación (Gonzáles e Illescas 2002).

Para finalizar, queremos hacer una exhortación a aquellos que exijan o prometan el cambio o Pachakutik. Sólo aquellos que asuman el autopachakutik o el cambio a nivel individual y en su propia familia, transformarán su energía-materia para volverse, en sí mismos, un paradigma no etnocéntrico ni antropocéntrico para otros seres humanos, en la propia o en otras sociedades y culturas. De otro modo, hablar de cambio, cuando lo que se pretende cambiar es al otro, a lo que está a mi alrededor, pero no a mí mismo, no representa más que un autoengaño y un engaño a los demás, que no tardará en desengañar a muchos. 


\section{Notas}

${ }^{1}$ La conjunción entre ideología y filosofía deviene de considerar a la ideología como una filosofía de vida, es decir, un conjunto de ideas o percepciones del mundo en general y de nosotros mismos.

${ }^{2}$ Ver: González Castro, Claudia. "Epistemologías Postcoloniales. Acerca del espacio de su génesis”.

${ }^{3}$ Entrevista con el sociólogo boliviano Manuel Salamanca.

${ }^{4}$ La pluralidad epistémica que demanda la postmodernidad no deja de constituir un "todo vale” (la tesis de Paul Feyerabend), sin más ni más, lo que a la larga también puede significar "nada vale”, dejando al más fuerte la posibilidad de imponer "lo que vale"

${ }^{5}$ Santiago Castro-Gómez es profesor de la facultad de Ciencias Sociales de la Pontificia Universidad Javierana en Bogotá e investigador titular del Instituto Pensar, de la misma universidad.

${ }^{6}$ Ver: Castro-Gómez, “Ciencias sociales, violencia epistémica y el problema de la «invención del otro»”.

${ }^{7}$ Ibíd.

${ }^{8}$ Racionalidad política es un concepto introducido por Foucault para mostrar cómo las diferentes variantes del sistema de poder definen, a través de un vocabulario y un discurso particular, el tipo de individuo que será funcional al logro de los objetivos perseguidos en el ejercicio del poder.

${ }^{9}$ Entre ellos: Enrique Dussel, Aníbal Quijano, Edgardo Lander, Walter Mignolo, Arturo Escobar, Fernando Coronil, Santiago Castro-Gómez, Catherine Walsh y el boliviano Javier Sanjinéz.

${ }^{10}$ El postoccidentalismo está concebido como "un proyecto crítico y superador del occidentalismo, que fue el proyecto pragmático de las empresas colonizadoras en las Américas desde el siglo XVI, desde el colonialismo hispánico, al norteamericano y al soviético” (Mignolo 1998). “(...) «post-occidentalismo» sería la palabra clave para articular el discurso de descolonización intelectual desde los legados del pensamiento en Latinoamérica. Digo «en Latinoamérica» y no «Latinoamericano», porque me es importante distinguir las historias locales (en Latinoamérica) de su esencialización geo-histórica (Latinoamericano). (Castro-Gómez 1996; cit. por Mignolo 1998).

${ }^{11}$ Ver Mignolo: “Espacios geográficos y localizaciones epistemológicas”. El semiólogo argentino Walter Mignolo es profesor de la Universidad de Duke (USA) donde coordina los programas de literatura latinoamericana y antropología cultural. Coedita la revista Disposition y la nueva serie de publicaciones Latin America Otherwise.

${ }^{12}$ Hugo Achúgar es poeta, ensayista e investigador uruguayo, parte importante del pensamiento crítico latinoamericano. Entre sus áreas de actuación figuran: las humanidades, las ciencias sociales, la sociología de la cultura y los estudios culturales. 
${ }^{13}$ Catherine Walsh es profesora principal y directora del doctorado en Estudios Culturales Latinoamericanos de la Universidad Andina Simón Bolívar, Sede Ecuador, donde también dirige el Taller Intercultural y la Cátedra de Estudios de la Diáspora Afro-Andina. Tiene una larga trayectoria acompañando los procesos de los movimientos indígenas y afrodescendientes en Abya Yala/América Latina.

${ }^{14}$ Ver: "Declaración de los Pueblos Indígenas. Llamamiento desde los Pueblos Indígenas frente a la Crisis de Civilización Occidental Capitalista” - Foro Social Mundial 2009, Belem, Amazonia, Brasil. En: http://www.aulaintercultural.org/article.php3?id_article=3204.

${ }^{15}$ Sobre la forma de hacer economía y juricidad desde el sentimiento de unidad con la totalidad, véase: “Dicotomías étnicas y filosóficas en la lucha por la descolonización” (referencias en Bibliografía); Mazorco, Graciela ( 2008), "De la competencia a la complementación: ¿Un nuevo paradigma en la economía?, Revista Polis, Universidad Bolivariana. Chile. En: http://redalyc.uaemex.mx/redalyc/pdf/305/30502114.pdf.,y Mazorco, Graciela (2008), "Inter e intraculturalidad y descolonización en el nuevo texto constitucional boliviano”. PROMEC-Universidad Mayor de San Simón. Cochabamba.

${ }^{16}$ Debemos aclarar que el término "filosofía”, aplicado a la sabiduría ancestral, es un préstamo de la lingüística occidental para poner ambas sabidurías en el mismo nivel de jerarquía, pero que, en sí mismo, expresa la no unidad entre el hombre y la naturaleza, así como la no unidad entre el filósofo y los objetos de conocimiento.

${ }^{17}$ Por ejemplo, Ludovico Berthonio, un jesuita experto en filología y lingüística, fue el extirpador de lenguas que acomodó el Jaque Aru o Aru Aru, idioma que hablaban los aymaras antes de la llegada española, a las exigencias de la evangelización. Con fines colonizadores, esta lengua fue torcida, antropocentrizada y convertida en el idioma aymara, a través del “Diccionario de la lengua aymara” que redactó Berthonio (Gonzáles e Illescas, 2003).

${ }^{18}$ El amauta inka, Dr. José Mario Illescas Pompilia, junto con su compañera: Mgr. Tatiana Gonzáles, han dado configuración conceptual a la cosmovisión y cosmovivencia de unidad originaria, y la han expresado en una serie de textos, algunos de los cuales consultamos en este documento. Elaboraron un sistema conceptual que denominamos: Filosofía de la Unidad. La misma contiene categorías ontológicas, gnoseológicas, epistemológicas y antropológicas que permiten revalorizar la visión de mundo de las culturas relegadas por la visión del hombre racional, y ponerla en pie de "semejanza-diferencia” (no corresponde decir "igualdad”, pues ésta no existe en la realidad) para debatir con la filosofía occidental. 


\section{Bibliografía}

Castro-Gómez, Santiago (2007), “Decolonizar la universidad. La hybris del punto cero y el diálogo de saberes”, en: Saavedra, José L (comp.), Educación Superior, interculturalidad y descolonización. Fundación PIEB, CEUB, La Paz. Bolivia.

Castro-Gómez, Santiago y Grosfogujel, Ramón (eds.) (2006), El giro decolonial. Reflexiones para una diversidad epistémica más allá del capitalismo global. Iesco-Pensar-Siglo del hombre Editores. Bogotá.

Castro-Gómez, Santiago, “Ciencias sociales, violencia epistémica y el problema de la «invención del otro»”. En: http://www.oei.es/salactsi/castro1.htm

Ídem (1998), “Latinamericanismo, mdernidad, globalización. Prolegómenos a una crítica postcolonial de la razón”, en Castro-Gómez, Santiago y Mendieta, Eduardo (coordinadores). Teorías sin disciplina. Latinoamericanismo, postcolonialidad y globalización en debate, Miguel Angel Porrúa, México.

Caudillo, Gloria Alicia, "Movimientos indígenas y la democracia: un diálogo intercultural” (México). En http://laventana.casa.cult.cu/ modules.php?name=News\&file=print $\&$ sid $=322$

González Castro, Claudia, “Epistemologías Postcoloniales. Acerca del espacio de su génesis”. En: http://www.rmm.cl/index_sub2.php?id _contenido=5647\&id_seccion=387\&id_portal=86

Gonzáles, Tatiana e Illescas, José (2002), Acerca de las Sociedades Indígenas o Diálogo Crítico con la Cientificidad Europea; Cinchaysuyu, Abya Yala; Ediciones Tukuy Ricqch’arina. Cochabamba, Bolivia.

Ídem (2002), Acerca de la educación en el mundo originario pre-inca en el territorio donde se formaría el Tahuantisuyo y el Qollasuyo; CEDIB Centro de Documentación e Información Bolivia. Cochabamba, Bolivia.

Lander, Edgardo (2001), "Pensamiento crítico latinoamericano: una impugnación del eurocentrismo”. En: Revista de Sociología. Santiago.

Ídem "Eurocentrismo y colonialismo en el pensamiento social latinoamericano”. En: http://www.tni.org/es/article/eurocentrismo-y-colonialismo-enel-pensamiento-social-latinoamericano

Mazorco, Graciela (2007), Filosofía, Ciencia y Saber Andino: Bases ontológicas, gnoseológicas y epistemológicas de la inter e intraculturalidad; POSGRADO FCE-UMSS, Cochabamba.

Mignolo, Walter (1998), "Postoccidentalismo: el argumento desde América Latina”. En: Teorías sin disciplina (latinoamericanismo, poscolonialidad y globalización en debate. Edición de Santiago Castro-Gómez y Eduardo 
Mendieta. México: Miguel Ángel Porrúa, 1998.

Ídem, "Espacios geográficos y localizaciones epistemológicas: la ratio entre la localización geográfica y la subalternización de conocimientos”. http:/ /www.javeriana.edu.co/pensar/Rev34.html

Ídem (2003), Historias Locales / Diseños Globales. Colonialidad, Conocimientos Subalternos y Pensamiento Fronterizo, Akal, Madrid.

Ídem, (1999), The Darker Side of de Renaissance. Literacy, Territoriality, \& Colonization, Ann Arbor: University of Michigan Press, 1955, p. 16, en: Alberto Moreiras, Tercer Espacio. Duelo y Literatura en América Latina, ARCIS/LOM Ediciones, Santiago.

Quijano, Aníbal (2000), “Colonialidad del poder y clasificación social”, en: Journal of Word-Systems Research Festschrift for Immanuel Wallerstein, Vol. 6, Number 3. Disponible en http://jwsr.ucr.edu/archive/vol6/number2/ pdf/jwsr-v6n2-quijano.pdf (nov-2007).

Walsh, Catherine (2007), “¿Son posibles unas ciencias sociales/culturales otras ¿ Reflexiones en torno a epistemologías decoloniales”. En: Revista Nómadas $\mathrm{N}^{\circ}$ 26, Disponible en http:/www.ucentral.edu.co/NOMADAS/ nunme-ante/26-30/26.htm (nov-2007).

Ídem (2006), “Interculturalidad y (de)colonialidad: diferencia y nación de otro modo”. En http://www.ram-wan.net/restrepo/decolonial/18-walshinterculturalidad\%20y\%20decolonialidad.pdf

Ídem (2005), “Introducción. (Re)Pensamiento crítico y (de)colonialidad. En: http://www.ram-wan.net/restrepo/decolonial/19-walsh-repensamiento\% 20critico.pdf

Ídem (2003), "Las geopolíticas del conocimiento y colonialidad del poder”. Entrevista a Walter Mignolo, en: Polis. Revista Académica Universidad Bolivariana, $\mathrm{N}^{\circ} 4$, Santiago.

Ídem (2003), “¿Qué saber, qué hacer y cómo ver? Los desafíos y predicamentos disciplinares, políticos y éticos de los estudios (inter)culturales desde América andina”, en Catherine Walsh, edit. Estudios culturales latinoamericanos. Retos desde y sobre la región andina, UASB/Abya-Yala, Quito.

Rivera, Silvia. 2006. “Chhiwinakax utwiwa. Una reflexión sobre prácticas y discursos descolonizadores”. En: http://www.ram-wan.net/restrepo/ decolonial/24-rivera-discursos\%20descolonizadores.pdf 